\title{
ANALISANDO AS INFLUÊNCIAS DAS PROPOSIÇÕES DA OCDE NAS POLÍTICAS EDUCACIONAIS NACIONAIS
}

\author{
ANALYZING THE INFLUENCES OF THE OCDE PROPOSITIONS IN NATIONAL \\ EDUCATIONAL POLICIES
}
ANALIZANDO LAS INFLUENCIAS DE LAS PROPOSICIONES DE LA OCDE EN LAS POLÍTICAS EDUCATIVAS NACIONALES

\author{
Susimeire Vivien Rosotti de Andrade \\ Universidade Estadual do Oeste do Paraná (UNIOESTE) \\ E-mail: susimeire.andrade@unioeste.br \\ Agência de fomento: Fundação Araucária \\ Patrícia Sândalo Pereira \\ Universidade Federal de Mato Grosso do Sul (UFMS) \\ E-mail: sandalo.patricia13@gmail.com
}

\begin{abstract}
RESUMO
Este artigo, derivado de um estudo teórico de uma tese, finalizada em 2020, busca apresentar uma investigação de natureza bibliográfica cujo objetivo consiste em apreender se, e como, as pesquisas produzidas por pesquisadores brasileiros desvelam as possíveis influências nas políticas educacionais brasileiras das proposições da Organização para a Cooperação e Desenvolvimento Econômico (OCDE). Para tanto, baseia-se na Perspectiva HistóricoCultural, que considera o ser humano um sujeito histórico, social e político. Os aspectos revelados se articularam em três categorias: 1) Apresentação de ideias e dados estatísticos; 2) Análise e avaliação das políticas educacionais, com enfoque na qualidade de ensino; 3) Análise e avaliação das políticas educacionais, com enfoque na formação de professores. Os resultados evidenciaram a influência das proposições dos OM, como a OCDE nas políticas educacionais brasileiras, assim, ao organizar os seus programas e plano, estas pautam-se na qualidade da educação que corroboram com os interesses do mercado, mas que não corroboram com uma educação escolar que permita, de fato, o cumprimento do direito de todos à educação como apropriação do conhecimento desenvolvido pela humanidade.
\end{abstract}

PALAVRAS-CHAVE: Organização para a Cooperação e Desenvolvimento Econômico (OCDE). Políticas Educacionais. Pesquisas brasileiras.

\section{ABSTRACT}

This article, derived from a theoretical study of a thesis completed in 2020, seeks to present an investigation of a bibliographic nature whose objective is to learn whether, and how, the research produced by Brazilian researchers unveils the possible influences on Brazilian educational policies of the Organization for Cooperation proposals and Economic Development (OECD). For that, it is based on the Historical-cultural Perspective that considers the human being a historical, social and political subject. The revealed aspects were divided into three categories: 1) Presentation of ideas and statistical data; 2) Analysis and evaluation of educational policies, focusing on the quality of teaching; 3) Analysis and evaluation of educational policies, with a focus on teacher training. The results showed the influence of the OM proposals, such as the OECD in Brazilian educational policies, thus, when organizing their programs and plans, they are guided by the quality of education that corroborate the interests of the market that do not corroborate with a school education that allows in fact, the fulfillment of everyone's right to education as the appropriation of knowledge developed by humanity.

KEYWORDS: Organization for Economic Cooperation and Development (OECD). Educational Policies. Brazilian research. 


\section{RESUMEN}

Este artículo, derivado del estudio teórico de una tesis, finalizada en 2020, busca presentar una investigación de carácter bibliográfico cuyo objetivo es conocer si, y cómo, la investigación producida por investigadores brasileños revela las posibles influencias en las políticas educativas brasileñas de las propuestas de la Organización para la Cooperación y Desarrollo Económico (OCDE). Para eso, se basa en la Perspectiva Histórico-Cultural que considera al ser humano como sujeto histórico, social y político. Los aspectos revelados se dividieron en tres categorías: 1) Presentación de ideas y datos estadísticos; 2) Análisis y evaluación de políticas educativas, con foco en la calidad de la enseñanza; 3) Análisis y evaluación de políticas educativas, con enfoque en la formación docente. Los resultados mostraron la influencia de las propuestas de MA, como la OCDE en las políticas educativas brasileñas, por lo que, al organizar sus programas y planes, se guían por la calidad de la educación que corroboran los intereses del mercado, pero que no corroboran con una educación escolar que permite, de hecho, el cumplimiento del derecho a la educación de toda persona como apropiación de los conocimientos desarrollados por la humanidade.

PALABRAS-CLAVE: Organización para la Cooperación y el Desarrollo Económicos (OCDE). Políticas educativas. Investigación brasileña.

\section{INTRODUÇÃO}

A Organização para a Cooperação e Desenvolvimento Econômico (OCDE) vem se tornando o principal organismo multilateral que influencia o processo de internacionalização das políticas educacionais. Ora, ela é a responsável pela elaboração e desenvolvimento do Programa Internacional de Avaliação de Estudantes (PISA), cujo resultado é utilizado para o ranking da qualidade da educação dos seus países membros ou parceiros, como Brasil, que participa do referido programa desde 2000.

Desse modo, os indicadores do PISA que são utilizados para avaliar os resultados dos sistemas de ensino intitulam-se competências, que vislumbram um guia prático para a compreensão do que ensinar e aprender aos jovens e adultos e, ainda, orientar os programas de formação para todos os estágios da aprendizagem.

Partindo disso, o presente artigo, resultante de um estudo teórico de uma tese, finalizada em 2020, no Programa de Pós-Graduação em Educação Matemática da Universidade Federal de Mato Grosso do Sul, apresenta um estudo bibliográfico a partir das pesquisas produzidas por pesquisadores brasileiros em que se desvelam as possíveis influências das propostas da OCDE nas políticas educacionais brasileiras utilizando, como metodologia, a análise de conteúdo. Objetivando-se apreender se, e como, as pesquisas produzidas por pesquisadores brasileiros desvelam as possíveis influências nas políticas educacionais brasileiras das proposições das OCDE. 
Este artigo está estruturado da seguinte forma: primeiro apresentam-se as orientações das OCDE no tocante à educação escolar, a seguir, analisam-se as pesquisas encontradas com a temática e finaliza-se com algumas considerações do que foi exposto.

\section{As orientações das OCDE no tocante à educação institucionalizada}

De acordo com Frigotto (2010), a educação escolar, no plano especificamente econômico, é vista como uma fatia do fundo público que se constitui em pressuposto de investimentos produtivos. Desse modo, a escola, que é a instituição social onde ocorre essa educação, não é poupada dos interesses econômicos, pautado no sistema capitalista. Partindo disso, a relação entre o processo econômico-social e a educação institucionalizada nas transformações do sistema capitalista enfatizam que o modelo empresarial vislumbra o mais eficiente a ser seguido e a classe dominante utiliza seu poder para estes serem introduzidos na escola.

Vale dizer que, após a Segunda Guerra Mundial, foram criados vários Organismos Internacionais (OI) visando a reconstrução dos países e, nesse período, a relação do Estado com a educação institucionalizada sofreu alterações motivada pelas transformações no sistema capitalista. Para Charlot (2013, p. 44), após a Segunda Guerra Mundial, a relação do Estado com a educação institucionalizada também se modifica, pois, a lógica preconizada pelas empresas é por ele adotada. Todavia, este continua a regulamentar a "ação econômica direta e se dedica à regulação das normas fundamentais e à manutenção dos equilíbrios sociais básicos”. Desse modo, "o Estado Regulador substitui o Estado Desenvolvimentista".

Ademais, Charlot (2013) considera que o fenômeno econômico e político denominado globalização, que vislumbra abertura de fronteiras, também afetou a educação institucionalizada e a compreensão destes deve partir de estudos de OI como: Banco Mundial (BM); a OCDE; o Fundo Monetário Internacional (FMI) e a Organização Mundial do Comércio (OMC).

Libâneo (2016) corrobora com essas ideias ao ressaltar que, no âmbito das políticas sociais, especialmente da educação, são atuantes, também, a Organização das Nações Unidas para a Educação, a Ciência e a Cultura - Unesco; o Banco Interamericano de Desenvolvimento (BID) e o Programa das Nações Unidas para o Desenvolvimento (PNUD). Nas palavras do autor, que confirma, por meio deste estudo, as implicações, no campo da educação, dessas investidas: 
[...] internacionalização significa a modelação dos sistemas e instituições educacionais conforme expectativas supranacionais definidas pelos organismos internacionais ligados às grandes potências econômicas mundiais, com base em uma agenda globalmente estruturada para a educação, as quais se reproduzem em documentos de políticas educacionais nacionais como diretrizes, programas, projetos de lei, etc. (LIBÂNEO, 2016, p. 43).

A citação esclarece que a internacionalização das políticas educacionais compõe o processo de globalização, que indica a necessidade de uma política internacional que oportunize o livre mercado de capitais, sendo assim, os organismos internacionais como: Unesco, BM, BID, PNUD e a OCDE, utilizam das conferências e reuniões internacionais para disseminar suas orientações.

Santomé (2011) agrega elementos importantes para estas discussões sublinhando que as proposições dos referidos organismos indicam que as crises econômicas, que geram desemprego em diferentes partes do planeta, têm como cerne para sua solução a educação institucionalizada e considera, também, que as reformas nos sistemas educacionais devem ser pautadas objetivando contribuir com as novas demandas da economia e da produção.

Cumpre lembrar que esta obediência se efetiva, pois os referidos organismos são os responsáveis em ditarem as regras no processo de globalização do Capital e suas avaliações são consideradas pelos grandes investidores, isto é, os donos do capital, em outras palavras, os países que tenham pareceres negativos terão prejuízos financeiros. De acordo com Freitas (2016), há um destaque da OCDE no processo da internacionalização das políticas educacionais, por ser herdeira do Plano Marshall e influenciar nestas políticas, pois passou a ser responsável pelo controle mundial na avaliação da qualidade de ensino de um país.

Segundo Pinto (2000, p.15), a OCDE iniciou suas ações no ano de 1960, quando foi assinado o Ato Constitutivo pelos países-membros da Organização Europeia para a Cooperação Econômica (OECE), além dos Estados Unidos e Canadá. Mas este organismo deu continuidade aos princípios de sua antecessora denominada OECE, procurando, assim, ser protagonista "na liberalização do comércio entre os países membros", e enfatiza que suas conclusões são recomendações, mas a trajetória histórica evidencia que acabava sendo seguida. Ademais, as transformações ocorridas com o fim da Guerra Fria e a globalização progressiva da economia internacional desencadeou a OCDE no final dos anos oitenta, a englobar países não membros, como o Brasil, e assim também influenciar as suas políticas. 
Cumpre lembrar que Petitat (1994, p. 216) sublinha que o desencadeamento da Guerra Fria, sinônimo de guerra econômica entre os países do Leste e do Ocidente, aumentou o investimento na educação, bem como nos estudos relacionando o "crescimento econômicosocial e a educação". Um desses intitula-se a "Teoria do Capital Humano", que foi sistematizada por um grupo de pesquisadores liderados por Theodoro Schultz, nos Estados Unidos, que partiu dos pressupostos teóricos da escola clássica liberal, isto é, dos estudos de pensadores como Adam Smith, e conclui o seguinte:

[...] a educação não é um consumo, mas um investimento que traz dividendos aos indivíduos (maior número de opções, salários mais elevados) e às coletividades (fator de crescimentos econômico). Um investimento insuficiente neste setor pode representar um entrave ao crescimento [...] os elementos do êxito e da competição individuais: maiores investimentos representavam uma espécie de garantia desta evolução (PETITAT, 1994, p. 217).

Desse modo, a Teoria do Capital Humano considera que o aluno deve investir em si próprio, adquirindo mercadorias (tecnologias e conhecimento), pois no futuro será um assalariado, concebido, pela sociedade, como um capitalista que joga no mercado de trabalho. Desse modo, os investimentos na educação pública realizados pelo Estado podem ser considerados como rentáveis, tendo em vista que vislumbram o desenvolvimento do país.

Assim, a referida teoria tem o cerne na manutenção do sistema capitalista e, para tanto, utiliza como defesa a perspectiva de que a educação é um investimento que possibilita o desenvolvimento econômico e, consequentemente, a distribuição de riqueza.

As proposições da OCDE para a educação escolar são pautadas pela Teoria do Capital Humano, como vislumbrado pela sua antecessora, a OECE. Segundo Charlot (2013), a OECE desenvolveu estudos na década de 1950, nos países-membros, acerca do seu sistema educacional, pois consideravam requisitos imprescindíveis para a ampliação do capital humano, que oportunizariam o crescimento econômico e o progresso social.

Para Santomé (2011, p. 163), apesar dos organismos internacionais enfatizarem a importância do investimento na educação institucionalizada, visando à melhoria na qualidade, a concepção pauta-se nos interesses do sistema econômico e, assim, o "investimento em educação aumentaria a produtividade, portanto, seus rendimentos futuros".

Nesse sentido, a trajetória da OCDE em relação à educação institucionalizada é marcada, primeiramente, como um organismo que indica parâmetros relacionados à função da mesma, avança como o responsável por fazer um levantamento de sua qualidade e consolida- 
se como um organismo com poder de influenciar as políticas educacionais dos governos dos Estados membros e parceiros.

Sacristán (2011) acrescenta que os relatórios da OCDE determinam a qualidade dos sistemas educacionais, que impactam as políticas dos governos dos Estados membros, com base nos seus resultados obtidos na avaliação externa que são tangíveis. Partindo disso, em 2000, a Education at a glace publicou uma série de indicadores acerca dos sistemas educacionais e, por meio de dados estatísticos, sublinha a escolarização nos diferentes níveis, financiamento, acesso, progresso e conclusão dos estudos, ambiente de aprendizagem e resultados em conteúdos básicos, obtidos no PISA.

Vale dizer que o PISA - preconizado e desenvolvido pela OCDE - tem uma relação direta com o projeto intitulado "Definição e Seleção de Competências Chave - DeSeCo", que iniciou em 1997, sob o seu patrocínio, e que, segundo Sacristán (2011, p. 26), tornou-se o guia desse organismo para traçar os caminhos para "avaliar e comparar sistemas a partir de uma visão mais complexa da educação", mas também quer se fixar em competências.

Sacristán (2011) considera que os indicadores para avaliar os resultados dos sistemas de ensino, intitulados competências, vislumbram um guia prático para a compreensão do que ensinar e aprender aos jovens e adultos e, ainda, orientar os programas de formação para todos os estágios da aprendizagem. É desse modo que a OCDE (2005) afirma que a competência não deve ser concebida como sinônimo de conhecimentos e habilidades, pois ela

[...] envolve a capacidade de enfrentar demandas complexas, apoiando-se em e mobilizando recursos psicossociais (inclusive habilidades e atitudes) em um contexto particular. Por exemplo, habilidade de comunicar-se efetivamente é uma competência que se pode apoiar no conhecimento individual da linguagem, de habilidades práticas em tecnologia e informação, e em atitudes em relação às pessoas com as quais se comunica (OCDE, 2005, p. 4, tradução nossa).

Desse modo, a OCDE considera que as competências determinam quais são os objetivos da educação que favorecem o desenvolvimento dos países, tendo em vista que apontam a formação necessária para os seres humanos conseguirem, no futuro, alcançar o sucesso na sociedade. Sacristán (2011) agrega elementos importantes para que se entenda essa questão enfatizando que o referido conceito de competência serve de referência para o PISA e seus relatórios indicam os possíveis problemas existentes nos sistemas de ensino, nos quais estes são desenvolvidos. Todavia, eles não oferecem subsídios para uma discussão que favoreça a sua solução, sendo muito semelhante às propostas que ocorreram na década de 1970, na qual a 
educação institucionalizada acabou sendo conduzida a seguir a ordenação hierarquizada, que relacionava a sua qualidade com a capacidade de melhor avaliar.

A OCDE concebe a qualidade de educação de um país partindo de uma análise das competências, que são os seus indicadores e despreza os motivos reais, que levam a tais resultados. Ora, como afirma Santomé (2011), o discurso das competências, nesse momento em plena atividade, obriga a prestar atenção a seu nascimento e a ver como, posteriormente, vai se modificando. No entanto, na realidade, o que se costuma fazer ao percorrer esse conceito é tratar de camuflar as filosofias que o geraram, acrescentando focos de atenção suplementares à medida que as críticas trazem à luz sua verdadeira face (SANTOMÉ, 2011, p. 163).

Mediante o exposto, ao considerar que o processo de internacionalização das políticas educacionais, orquestrado por organismos como OCDE, visam interesses econômicos, que prejudicam que a educação escolar cumpra a sua função social. Segue a análise das pesquisas encontradas para evidenciar possíveis influências, como as aqui elencadas, nas políticas educacionais brasileiras.

\section{Aspectos metodológicos}

Ao objetivar apreender se, e como, as pesquisas produzidas por pesquisadores brasileiros desvelam as possíveis influências nas políticas educacionais brasileiras realizou-se um estudo bibliográfico, no período de março de 2017 a agosto de 2018, partindo do Banco de Teses \& Dissertações da Coordenação de Aperfeiçoamento de Pessoal de Nível Superior CAPES, no qual estão disponibilizadas as teses e dissertações desenvolvidas no país desde 1987. Também optou-se pelo conjunto de técnicas de análise das comunicações, "análise de conteúdo", na qual Bardin (2016), considera que esta oportuniza ao pesquisador o conhecimento que está por trás das palavras, sobre os quais se debruça, e busca outras realidades por meio de mensagens, pois engloba diversas áreas de pesquisa sendo composta de polos cronológicos.

Desse modo, o primeiro polo cronológico da análise de conteúdo é a "pré-análise", na qual escolhem-se os documentos que poderão constituir o corpus, pois, para Bardin (2016), o pesquisador pode traçar caminhos para decisão. Dessa forma, ao considerar que o objetivo do estudo bibliográfico é apreender se, e como, as pesquisas produzidas por pesquisadores brasileiros desvelam as possíveis influências nas políticas educacionais brasileiras e, consequentemente, na educação escolar das proposições das OCDE, optou-se em apreender se, 
e como, as pesquisas produzidas por pesquisadores brasileiros desvelam as possíveis influências nas políticas educacionais brasileiras. Partindo disso, utilizou-se a palavra-chave “OCDE” refinando para teses e programas: Educação; Ensino e Educação Matemática, visto que, é nele que a autora principal deste artigo desenvolveu sua pesquisa de doutorado.

Após a leitura flutuante, que compõe o primeiro polo cronológico da análise de conteúdo, aproximou-se dos documentos e elaborou-se o gráfico 1, que indica que somente no século XXI há um destaque pela OCDE e, como já enfatizado anteriormente, a influência deste organismo, que pode ser considerada herdeira das proposições realizadas após a Segunda Guerra Mundial visando a reconstrução dos países, sua criação motiva atender o sistema econômico.

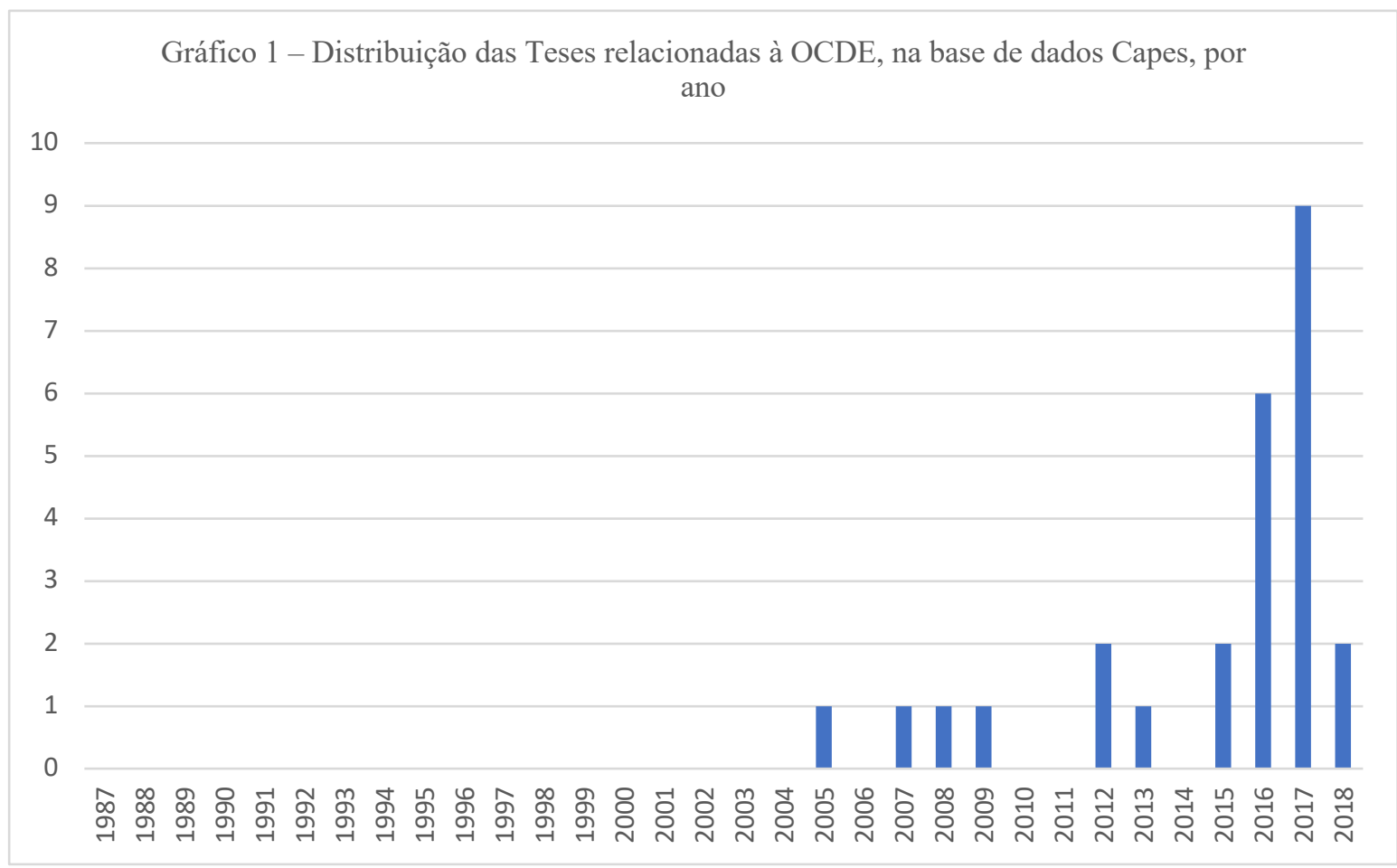

Fonte: Elaborado pelas autoras, a partir do Portal da CAPES, 2018.

Mediante o exposto, dando continuidade ao primeiro polo cronológico da análise de conteúdo, há a escolha dos documentos que constituirão o corpus. Para Bardin (2016), a constituição do corpus acarreta ao pesquisador algumas escolhas que são efetuadas tendo como pressupostos as seguintes regras: exaustividade, representatividade e pertinência. A primeira indica que o pesquisador, ao deixar de analisar um documento, deve justificar a decisão; a segunda, que os documentos tenham o mesmo tema, e a última regra indica que é imprescindível que haja a correlação com os objetivos traçados à análise. Optou-se em não 
analisar as teses que não apresentavam indícios de materialização das influências da OCDE nas políticas educacionais do Brasil.

Dessa forma, os seguintes documentos constituem o corpus: Sossai (2017); Bastos (2017); Petronzelli (2016); Pereira (2016), Chirinéa (2016), Castelli Jr (2016), Hofmann (2013); Ramos (2012); Rodrigues (2017); Schimonek (2017); Fraga (2017); Coelho (2017); Batista (2017); Ferreira (2012); Silva (2015); Rosa (2017); Aguiar (2018) e Rocha (2009).

Ao constituir o corpus, partiu-se para o segundo polo cronológico denominado “exploração do material”. Para Bardin (2016, p. 131), “se as diferentes operações da pré-análise forem convenientemente concluídas, a fase de análise propriamente dita, não é mais do que a aplicação sistemática das decisões tomadas”. Diante disso, é necessário escolher as regras da organização da codificação que podem ser as seguintes: o recorte, a enumeração, a classificação e a agregação. No "recorte", o pesquisador escolhe a unidade registro e de contexto, sendo que a de contexto favorece compreender a de registro.

Nas palavras de Bardin (2016, p. 107-108), a "unidade de registro" deve ser conceituada como "unidade de significação a ser codificada e corresponde ao menor segmento de conteúdo a ser considerado como unidade de base, visando à categorização, podendo ser de natureza e dimensões variadas".

Com relação à escolha de organização da codificação denominada "enumeração", a autora indica que o pesquisador, após distinguir a unidade de registro com o que se conta, terá que indicar como realizará a contagem. Indo além, tem-se a classificação e a agregação. Nesta escolha, o pesquisador avança na decisão das categorias que "são rubricas ou classes, que reúnem um grupo de elementos (unidades de registro, no caso da análise de conteúdo) sob um título genérico, agrupamento esse efetuado em razão dos caracteres comuns destes elementos" (BARDIN, 2016, p. 108).

Assim, considerando o objetivo estabelecido na pré-análise, que é apreender se, e como, as pesquisas produzidas por pesquisadores brasileiros desvelam as possíveis influências nas políticas educacionais brasileiras e, consequentemente, na educação institucionalizada das proposições da OCDE, as categorias foram formadas utilizando-se de indicadores que as une na mesma temática, como verifica-se no Quadro 1. 


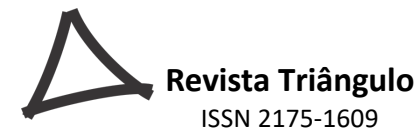

Quadro 1: Indicadores e categorias do estudo dos documentos

\begin{tabular}{|l|l|l|}
\hline Indicador & Categoria & Teses \\
\hline Ideias e dados & $\begin{array}{l}\text { Apresentação de ideias e dados } \\
\text { estatísticos }\end{array}$ & Sossai (2017) e Bastos (2017). \\
\hline $\begin{array}{l}\text { Indicadores de } \\
\text { avaliação da } \\
\text { qualidade do } \\
\text { ensino }\end{array}$ & $\begin{array}{l}\text { Análise e avaliação das políticas } \\
\text { educacionais, com enfoque na } \\
\text { qualidade de ensino }\end{array}$ & $\begin{array}{l}\text { Petronzelli (2016); Pereira (2016), } \\
\text { Chirinéa (2016), Catelli Jr (2016), } \\
\text { Rofmann (2013); Ramos (2012); } \\
\text { (2017) e Fraga (2017). Schimonek }\end{array}$ \\
\hline $\begin{array}{l}\text { Formação de } \\
\text { professores }\end{array}$ & $\begin{array}{l}\text { Análise e avaliação das políticas } \\
\text { educacionais, com enfoque na } \\
\text { formação de professores }\end{array}$ & $\begin{array}{l}\text { Coelho (2017); Batista (2017); } \\
\text { Ferreira (2012); Silva (2015); Rosa } \\
\text { (2017); Aguiar (2018) e Rocha } \\
(2009) .\end{array}$ \\
\hline
\end{tabular}

Fonte: Elaborado pelas autoras, 2018.

Segue, nos próximos subitens, o tratamento dos dados, sendo este o último polo cronológico da análise de conteúdo, e sua efetivação ocorre por meio de inferência e da interpretação dos resultados, assim, apoiado no referencial teórico, adotado no trabalho, permite ao pesquisador ir além da aparência chegando à essência, obtendo o conhecimento.

\section{Apresentação de ideias e dados estatísticos}

Na primeira categoria, denominada “Apresentação de ideias e dados estatísticos”, estão os documentos que têm como temática "ideia e dados" e objetiva apreender as influências das orientações da OCDE que versam sobre os dados estatísticos acerca do Brasil, que foram realizadas pelo referido organismo antes de propor as possíveis soluções. No corpus são os seguintes trabalhos, assim, categorizados: Sossai (2017) e Bastos (2017).

De acordo com Instituto Nacional de Estudos e Pesquisas Educacionais Anísio Teixeira - INEP, órgão integrante da estrutura do Ministério da Educação e do Desporto, responsável pela avaliação da educação brasileira,

O programa de educação da OCDE vem trabalhando nos últimos dez anos para melhorar os indicadores internacionais de desempenho educacional. Para tanto, a OCDE decidiu investir diretamente na melhoria das medidas de resultados, organizando pesquisas internacionais comparáveis, enfocando especialmente medidas de habilidades e competências necessárias à vida moderna. O PISA insere-se dentro deste propósito (BRASIL, 2011, p. 08).

Neste sentido, Sossai (2017) e Bastos (2017) desenvolveram pesquisa bibliográfica e documental sendo que a primeira analisou as relações transcorridas no interior de organizações internacionais como o BM - Banco Mundial, a Organização Mundial do Comércio e a 
Organização para a Cooperação e Desenvolvimento Econômico (OCDE), no período compreendido entre 1960 e 1992. A segunda pesquisou, além dessas duas organizações multilaterais, o FMI, investigando os influxos da economia política global sobre a educação básica pública, elucidando as causas estruturais que contribuem para a deterioração dos sistemas públicos básicos de ensino.

Cumpre lembrar que os pesquisadores utilizaram pressupostos teóricos diferentes em suas pesquisas. Sossai (2017) partiu do realismo crítico e da filosofia da tecnologia, enquanto Bastos (2017) do Materialismo Histórico-Dialético. Mas, ambos concluíram que as organizações multilaterais objetivam um modelo educacional que não corrobora para $o$ processo de ensino e aprendizagem dos alunos.

Bastos (2017, p. 08) afirma, ainda, que a influência dessas organizações multilaterais vislumbra um "modelo educacional imediatista, mercantil e adestrador que fracassou, por onde foi adotado, em lograr os declarados objetivos de recuperar o nível de desempenho educacional e de eliminar a diferença de desempenhos entre os discentes”. Nas palavras de Sossai (2017):

[...] discussão histórica e educacional sobre processos de formação de consenso edificados por intermédio de acionamentos aos gabinetes da OCDE, bem como uma análise dos interesses específicos de alguns atores (individuais e coletivos) que, no transcurso das décadas de 1960 a 90, agiram nos bastidores da instituição para garantir que a articulação entre educação e tecnologia seria um projeto de futuro para os Estados que orbitavam ao redor da organização (SOSSAI, 2017, p. 06).

As pesquisas corroboram com Freitas (2012) que afirma que a nova investida nas políticas educacionais brasileira traz os velhos atores que são, para eles, os empresários que utilizam de novos mecanismos de pressão, entre eles a OCDE que, desde a década de 1990, mostram sua força, por serem quem elaborou os dados estatísticos que evidenciam os problemas dos países relacionados à educação. Com os referidos dados, a OCDE tem condições de indicar os problemas quantitativos na educação do país e, assim, lança sua nova ofensiva para indicar a qualidade em educação, que deverá ser seguida como apontado nas teses a seguir.

\section{Análise e avaliação das políticas educacionais, com enfoque na qualidade de ensino}

A segunda categoria denomina-se "Políticas Educacionais, com enfoque nas reformas educacionais e financiamento da educação". Nesta categoria estão os documentos que têm como temática "Indicadores de avaliação da qualidade do ensino", e visa examinar e tecer inferências das influências das orientações da OCDE que versam sobre avalições na educação básica que se materializaram no Brasil. No corpus encontram-se os seguintes autores: 
Petronzelli (2016); Pereira (2016), Chirinéa (2016), Catelli Jr (2016), Hofmann (2013); Ramos (2012); Rodrigues (2017); Schimonek (2017) e Fraga (2017).

Petronzeli (2016, p. 07) desenvolveu uma pesquisa bibliográfica e documental, que trata das políticas avaliativas para educação básica brasileira e conduz o estudo, ao sistematizar o Campo da Literacia e seu desenvolvimento na Organização para a Cooperação e Desenvolvimento Econômico/OCDE e, finalmente, sua expressão no Programa Internacional de Avaliação de Alunos/PISA. Partindo do Materialismo Histórico-Dialético conclui que o “conceito de literacia e literacia matemática - exprime as determinações expressas em programas internacionais de avaliação. Políticas avaliativas para educação básica brasileira a partir do Programa Internacional de Avaliação de Alunos/PISA da OCDE”.

Com relação à tese de Chirinéa (2016), a autora investigou como as escolas pertencentes ao sistema municipal de ensino de Bauru, que contemplam o nível fundamental de educação do município, se apropriaram do resultado do IDEB para instituir ações no interior do ambiente escolar. Conclui que as recomendações da OCDE preconizadas no Plano de Desenvolvimento da Educação e pelo Plano de Metas Compromisso Todos pela Educação, apontam os resultados do IDEB como fundamental na análise da qualidade educacional e se tornaram o único referencial de análise nas escolas investigadas.

As conclusões de Chirinéa (2016) corroboram com Brasil (2016) no qual o Plano Nacional de Educação (PNE 2014-2024, Lei no 13.005/2014), indica que na estratégia onze da meta sete, o PISA é considerado um instrumento externo de referência na avaliação de aprendizagem de estudantes brasileiros da Educação Básica.

Catelli Jr (2016); Rodrigues (2017); Pereira (2016) e Schimonek (2017) analisaram como o processo de internacionalização das políticas educacionais influenciaram diferentes países realizando uma comparação entre os impactos relativos aos processos de avaliação, as propostas de inclusão e aos programas governamentais de educação em tempo integral.

Em seu estudo, Catelli Jr (2016) partiu de uma perspectiva comparada entre as políticas públicas de certificação de jovens e adultos, por meio de exames nacionais para pessoas jovens e adultas desenvolvidas no Brasil, no Chile e no México, e a inserção dessas políticas em uma governança internacional, mediada por organismos como o BM, a OCDE e a UNESCO, responsável pela organização das Conferências Internacionais de Educação de Adultos (CONFINTEA). Concluiu que os exames não têm se constituído em uma política efetiva de democratização de oportunidades para estes jovens e adultos. 


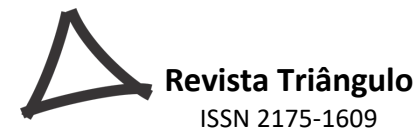

Fraga (2017) também analisou as políticas educativas de jovens e adultos, mas apenas no Brasil, investigando seus contornos na transição do milênio, entre 2000 e 2015, bem como suas relações com a Agenda Globalmente Estruturada para a Educação (AGEE), e os tensionamentos promovidos no âmbito da sociedade civil. Concluiu que as análises realizadas permitem afirmar a incidência da lógica neoliberal expressa nas orientações dos Organismos Internacionais sobre as políticas educativas de EJA que vêm se desenvolvendo no Brasil, no qual a reconfiguração do papel do Estado, voltado para responder às demandas do mercado, em detrimento das demandas da sociedade civil.

Pereira (2016) desenvolveu uma pesquisa bibliográfica e documental analisando os pressupostos epistemológicos subsumidos nas concepções de qualidade da educação, presentes no Programa Internacional de Avaliação de Estudantes (PISA) da Organização para a Cooperação e Desenvolvimento Econômico (OCDE), buscando identificar como tais pressupostos influenciam as políticas educacionais no Brasil e na Espanha, tomando como referência as leis nacionais contemporâneas: Plano Nacional de Educação (2014-2024) e Ley Orgánica para la Mejora de la Calidad Educativa (LOMCE). Assim, concluindo que na perspectiva da organização, asseguram a qualidade na educação, quais sejam: insumos (inputs), processo e resultados (outputs).

Rodrigues (2017), investigou quais as tendências internacionais e locais das políticas de inclusão que permearam o Ensino Superior após a Declaração Mundial sobre Ensino Superior de 1998, e de que maneira apontam para construção de culturas, políticas e práticas de inclusão e exclusão. Partindo de um cunho hermenêutico identificou algumas tendências internacionais subjacentes nas políticas de inclusão em educação, bem como quais delas estão presentes na realidade brasileira. Desse modo, sua influência perpetua também nas políticas de inclusão em educação.

Schimonek (2017), ao analisar dois programas governamentais de educação em tempo integral no Brasil (Programa Mais Educação) e Portugal (Escola a Tempo Inteiro), bem como suas implicações na diminuição das desigualdades educacionais em ambos os países, concluiu que ambos os programas de educação em tempo integral associam-se às orientações e diretrizes de organismos internacionais como OCDE e BM, que compreendem tais ações governamentais (programas) como mecanismos para a diminuição de desigualdades educacionais e promoção de um ensino de qualidade, cuja eficácia é aferida por resultados obtidos em avaliações de larga escala. 

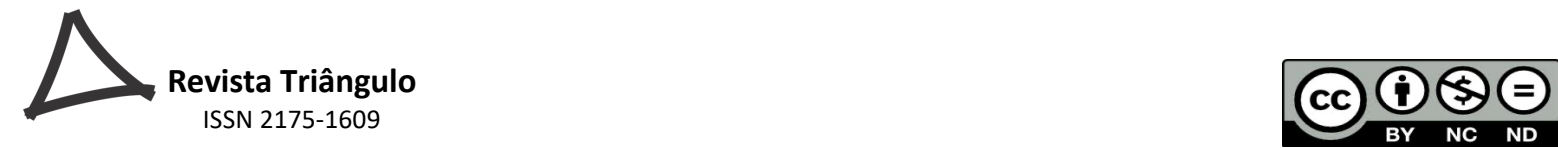

Esse estudo lembra as palavras de Freitas (2016), ao referir-se que a aprendizagem, ao ser controlada por organismos externos como OCDE, tem como cerne indicar que os resultados têm como responsáveis a comunidade escolar e, apesar de afirmar os impactos na aprendizagem oriundos dos problemas sociais dos alunos, ressaltam que a educação institucionalizada é capaz de solucionar esse problema. No entanto, para que ocorram mudanças na qualidade da educação, o cerne é uma investigação "sistemática nos processos de mobilização das forças internas que movem a escola".

A tese de Ramos (2012) teve como objetivo compreender as ressignificações do discurso pedagógico contemporâneo, a partir da análise dos slogans que circularam na recente Conferência Nacional de Educação (CONAE). Para abordar a constituição ideológica deste lugar, nos seus sentidos hegemônicos, foram analisados os discursos da OCDE e imagens de professores na mídia como expressões das relações entre os contextos micro e macro. Concluiu que os slogans ganham centralidade no discurso pedagógico contemporâneo, na tentativa de perceber sentidos que interpelam sujeitos e sistemas de ensino e vão sendo naturalizados, até que, tomados como necessários, afastam possibilidades de crítica.

As teses aqui elencadas corroboram com os estudos de Freitas (2016) que afirma que a OCDE tem uma relação direta com os velhos atores, isto é, com os grandes empresários donos do capital, pois são eles que administram o referido organismo e, localmente, contam com o apoio das organizações dirigidas e financiadas por eles, que responsabiliza a comunidade escolar pelos problemas existentes como será apresentado no último eixo.

\section{Análise e avaliação das políticas educacionais, com enfoque na formação de professores}

A terceira categoria, intitulada "Políticas Educacionais, com enfoque na formação de professores", objetiva examinar e tecer inferências das influências das orientações da OCDE, que versam sobre a formação dos professores que se materializaram no Brasil. Assim, no corpus são apresentados os seguintes estudos: Coelho (2017); Batista (2017); Ferreira (2012); Silva (2015); Rosa (2017); Aguiar (2018) e Rocha (2009).

A tese de Batista (2017) objetivou identificar as aproximações e os distanciamentos entre documentos produzidos pela UNESCO e pela OCDE como recomendações para a educação de caráter planetário; documentos da política educacional nacional (Diretrizes Curriculares Nacionais para formação de professores da Educação Básica e para o curso de Pedagogia) e Projeto Políticos Pedagógicos (PPCs) de Pedagogia de sete universidades públicas 
federais na Amazônia. As singularidades foram relacionadas com a organização do currículo e com as diferenças de sentidos atribuídos aos termos que compõem o léxico da política educacional, a exemplo das competências.

Ferreira (2012) tinha como objetivo identificar e analisar a regulação da política de formação docente no Brasil para a educação básica, no período de 2007 a 2010, e suas relações com as orientações da OCDE. Concluiu que a política de formação docente no Brasil vem enfatizando a agenda de desenvolvimento social, econômico e educacional da OCDE. Registrase que a preocupação do governo brasileiro com os professores "eficazes", com escolas de "sucesso" e o conteúdo nelas transmitidos ocupa centralidade na agenda da política educacional, por meio da "cultura dos resultados", via as avaliações internas e externas.

A tese de Silva (2015) apresenta uma análise das políticas educacionais que tratam da inovação no trabalho docente, determinadas pela governança global, especialmente na perspectiva da OCDE . Concluiu que as ações e políticas brasileiras têm muitas características dos parâmetros preconizados pela OCDE.

Com relação à tese de Rosa (2017), esta objetivou compreender a articulação entre o conhecimento pericial emanado da OCDE e a política pública, formulada e implementada para a formação inicial/profissionalização de professores no Brasil e em Portugal pelos decisores políticos, no período de 1990-2013. Concluiu que tanto no Brasil quanto em Portugal, as políticas de formação inicial de professores foram forjadas no tripé representações, conhecimento e regulação, a partir de um 'novo' modelo de profissão docente estruturado em quatro dimensões, a saber: o alargamento de tarefas, o desenvolvimento de competências, a gestão do corpo docente e a aprendizagem ao longo da vida. Em ambos os contextos são preconizadas as 'boas práticas' e os 'bons exemplos' como instrumento de regulação para as ações públicas de formação inicial/profissionalização de professor.

A tese de Aguiar (2018) teve como objetivo elucidar, nos processos de governança erigidos a partir da última transição milenar, a estratégia político-educacional conduzida pelas Organizações Multilaterais em prol da construção de standards docentes nos sistemas educacionais. Partiu dos pressupostos do Materialismo Histórico-Dialético e análise bibliográfica sobre a temática e do exame dos documentos das Organizações Multilaterais. Concluiu que a persistente recomendação em favor da construção de standards docentes indica uma estratégia abrangente, que tem buscado consolidar um poderoso mecanismo de governança sobre os professores, com o propósito de interceder, de forma desigual e combinada, no 
delineamento de docentes capazes de adequar os processos educativos às características de produção dos seus Estados-Nações na dinâmica do capital-imperialismo, bem como às necessidades de reprodução das formas de sociabilidade compatível com os interesses dominantes.

A tese de Rocha (2009) analisou as políticas de valorização do magistério realizadas pela Prefeitura Municipal de Belo Horizonte, durante os governos de 1993 a 2007, considerando os elementos: condições de trabalho, jornada de trabalho e plano de carreira. Este estudo possibilitou perceber que as políticas de valorização do magistério, nos aspectos que se referem à remuneração, carreira e condições de trabalho, estão historicamente entrelaçadas à problemática da qualidade do ensino.

A tese de Coelho (2017) analisa as políticas educacionais para o ensino superior brasileiro, partindo das políticas de Formação de Professores, com ênfase no Plano Nacional de Formação de Professores da educação básica (PARFOR), ditas políticas de universalização ao ensino superior devido à falta de professores. Partindo do materialismo histórico-dialético enquanto método de análise, postura política e concepção de homem e sociedade evidenciou, em suas conclusões, que o PARFOR nada mais é do que um dos programas emergenciais que objetiva a formação de professores resilientes fundamentais para a obtenção do consenso ativo das classes subalternas e da manutenção da hegemonia neoliberal. Dessa forma, os professores acabam sendo submetidos à racionalidade neoliberal por meio de um processo de certificação em massa.

\section{CONSIDERAÇÕES FINAIS}

Este artigo apreendeu se, e como, as pesquisas produzidas por pesquisadores brasileiros desvelam as possíveis influências nas políticas educacionais brasileiras. Realizou-se, então, um levantamento bibliográfico tomando como base os resumos das teses presentes no banco de dados da CAPES, que foram analisados, utilizando-se do método da análise de conteúdo de Bardin (2016).

O levantamento bibliográfico localizou trinta teses e constatou que o interesse pelo tema coincide com o período no qual a OCDE avançou como o organismo internacional responsável pelo levantamento e avaliação da qualidade de educação dos governos dos estados membros e parceiros, consolidando sua influência nas políticas educacionais. 
Assim, das trinta teses, inicialmente identificadas, apenas dezoito vão ao encontro do objetivo da pesquisa que, devido aos aspectos revelados, se articularam em três categorias: 1) Apresentação de ideias e dados estatísticos; 2) Análise e avaliação das políticas educacionais, com enfoque na qualidade de ensino; 3) Análise e avaliação das políticas educacionais, com enfoque na formação de professores.

Desse modo, as duas teses que se enquadram na categoria "Apresentação de ideias e dados estatísticos", concluem que a OCDE analisou o sistema educacional dos governos dos Estados membros e parceiros, como o Brasil, para obter dados e apresentá-los partindo de sua concepção acerca da qualidade na educação e dos relativos problemas existentes.

Na categoria “Análise e avaliação das políticas educacionais, com enfoque na qualidade de ensino", as nove teses enfatizaram a influência nas políticas educacionais brasileiras, pois o PNE considera o PISA, que é organizado pela OCDE, como adequado para conseguir medidas de habilidades e competências necessárias à vida moderna.

Nesta categoria verificou-se, também, a influência de Organismos Internacionais, como a OCDE, no que tange ao Programa Mais Educação e em políticas educacionais relacionadas à inclusão e EJA, favorecendo, assim, que a concepção de qualidade de educação vislumbre os interesses daqueles que eles representam, isto é, o mercado, prejudicando que sejam atendidas as demandas da sociedade civil.

Na categoria "Análise e avaliação das políticas educacionais, com enfoque na formação de professores" que trata da análise e avaliação das políticas educacionais, com enfoque na formação de professores, sete teses a contemplam. Nesta categoria identificou-se que programas como o PARFOR, ao serem influenciados por organismos como a OCDE, atendem ao interesse do mercado, proporcionando uma certificação em massa e distanciando-se do seu objetivo inicial, que era contribuir com a formação dos professores que atuam na educação básica sem a formação adequada.

Vale dizer que, também, são enfatizadas características dos parâmetros preconizados pela OCDE, que responsabilizam os professores, individualmente, como capazes de solucionar os problemas da qualidade da educação, pois entendem boas práticas e bons exemplos como o caminho. Nesse estudo, que corrobora com o preconizado por Freitas (2016), a qualidade da educação deve ser concebida como algo que relaciona vários fatores que perpassam a sociedade e, ao indicar que sua solução ocorrerá a partir de uma ação individual, corrobora para que não se discutam quais são os verdadeiros responsáveis. 


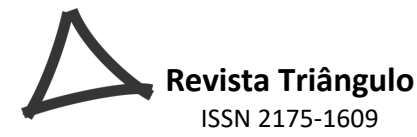

Ao considerar os interesses que pautam a OCDE, evidencia-se que estes não corroboram com uma educação institucionalizada que permita, de fato, o cumprimento do direito de todos à educação. Neste sentido, a defesa da educação escolar, no atual estágio do sistema capitalista, é primordial, pois a complexidade que a permeia evidencia, ainda mais, a apropriação do conhecimento desenvolvido pela humanidade, favorece o homem a compreender que lhe negar acesso ao conhecimento, o prejudica na sua construção histórica, social e política, e o leva a considerar a dominação e a exploração como algo natural.

\section{REFERÊNCIAS}

AGUIAR, E. S. S. Governança supranacional e a política desigual e combinada para a construção de standards docentes. 2018, 193 f. Tese (Doutorado em Educação) Universidade Federal de Santa Catarina, Florianópolis. Biblioteca Depositária: BU UFSC Disponível em: http://ppge.ufsc.br/. Acesso em: 25 maio 2018.

BARDIN, L. Análise de conteúdo. 70. ed. São Paulo: Edições, 2016.

BASTOS, R. M. B. No Profit Left Behind: os efeitos da economia política global sobre a educação básica pública. 2017, 326 f. Tese (Doutorado em Educação). Universidade Federal do Ceará, Fortaleza. Biblioteca Depositária: Repositório Institucional/Universidade Federal do Ceará. Disponível em:

http://www.repositorio.ufc.br/bitstream/riufc/28494/3/2017 tese_rmbbastos.pdf. Acesso em: 25 maio 2018.

BATISTA, E. R. M. Educação em ciências naturais no currículo de cursos de pedagogia de universidades públicas federais da Amazônia legal brasileira. 2017. $214 \mathrm{f}$. Tese (Doutorado em Educação em Ciências e Matemática). UFMT - UFPA - UEA. Cuiabá-MT.

BRASIL. De olho nas metas 2011: Quarto relatório de monitoramento das 5 Metas do Todos Pela Educação. 2011.

https://www.todospelaeducacao.org.br/arquivos/biblioteca/de_olho_nas_metas_2011_tpe.pdf Acesso em: 02 maio 2018.

BRASIL. Instituto Nacional de Estudos e Pesquisas Educacionais Anísio Teixeira (INEP). Pisa 2015: análises e reflexões sobre o desempenho dos estudantes na avaliação. São Paulo: Fundação Santillana, 2016. Disponível em:

http://download.inep.gov.br/acoes_internacionais/pisa/resultados/2015/pisa2015_completo_fi nal_baixa.pdf. Acesso em: 03 maio 2018.

CASTELLI JR, R. Políticas de certificação por meio de exames nacionais para a

Educação de Jovens e Adultos: um estudo comparado entre Brasil, Chile e México. 2016. 326 f. Tese (Doutorado em Educação). Universidade de São Paulo, São Paulo. Biblioteca depositária: FEUSP. Disponível em: https://www.teses.usp.br/teses/disponiveis/48/48134/tde15092016-144248/pt-br.php . Acesso em: 23 maio 2018. 


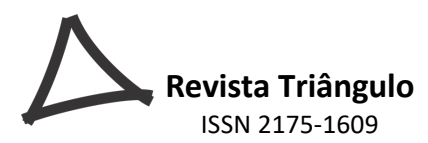

COELHO, H. R. Formação de professores em tempos neoliberais: crítica ao Parfor enquanto política de resiliência. 2017. 356 f. Tese (Doutorado em Educação). Universidade Federal Fluminense. Niterói-RJ. Disponível em:

file://C:/Users/susiv/Downloads/2017\%20Tese\%20Higson\%20Rodrigues\%20Coelho.pdf. Acesso em: 25 maio 2018.

CHARLOT, B. Da relação com o saber: elementos para uma teoria. Trad. Bruno Magne. Porto Alegre: Artes Médicas Sul, 2013.

CHIRINÉA, A. M. Gestão da escola pública municipal e utilização do ideb: as "traduções" no contexto da prática. 2016. 181 f. Tese. (Doutorado em Educação). Universidade Est. Paulista Júlio de Mesquita Filho/Marília. Biblioteca depositária: Campus de Marília. Disponível em:

file://C:/Users/susiv/Downloads/Tese $\% 20$ Vers $\%$ C3\%A30\%20Final $\% 20$ Andr $\% \mathrm{C} 3 \% \mathrm{~A} 9 \mathrm{ia} \% 2$ 0Melanda.pdf Acesso em : 23 maio 2018.

FERREIRA, D. L. A Organização para a Cooperação e Desenvolvimento Econômico (OCDE) e a política de formação docente no Brasil. 2012. $330 \mathrm{f}$. Tese (Doutorado em Educação). Universidade Federal de Pará. Belém - PA. Disponível em:

http://repositorio.ufpa.br/jspui/bitstream/2011/2738/1/Tese_OrganizacaoCooperacaoDesenvol vimento.pdf. Acesso em: 25 maio 2018.

FRAGA, E. R. Política educativa de jovens e adultos no Brasil no contexto da agenda globalmente estruturada para educação. 2017. 175 f. Tese (Doutorado em Educação). Universidade Federal do Espírito Santo -Vitória. Biblioteca depositária: Biblioteca Central UFES. Disponível em: https://repositorio.ufes.br/handle/10/8534. Acesso em: 25 maio 2018.

FREITAS, L. C. Três teses sobre as reformas empresariais da educação: perdendo a ingenuidade. Cad. Cedes, Campinas, v. 36, n. 99, p. 137-153, maio-ago., 2016.. Disponível em: http://www.scielo.br/pdf/ccedes/v36n99/1678-7110-ccedes-36-99-00137.pdf. Acessado em: 20 jun. 2018.

FRIGOTTO, G. A produtividade da escola improdutiva: um (re)exame das relações entre a educação e a estrutura econômico-social capitalista. 9. Ed. São Paulo: Cortez, 2010.

LIBÂNEO, J. C. Políticas educacionais no Brasil: desfiguramento da escola e do conhecimento escolar. Cadernos de Pesquisa, v. 46 n.159 p.38-62 jan./mar. 2016. Disponível em: http://www.scielo.br/pdf/cp/v46n159/1980-5314-cp-46-159-00038.pdf. Acesso em: 11jul. 2017.

HOFMANN, R. M. Educação financeira no currículo escolar: uma análise comparativa das iniciativas da Inglaterra e da França. 2013. 330 f. Tese (Doutorado em Educação).Universidade Federal do Paraná - Curitiba. Biblioteca depositária: Biblioteca do Setor de Ciências Humanas. Disponível em: https://acervodigital.ufpr.br/handle/1884/31860 Acesso em: 25 maio 2018. 


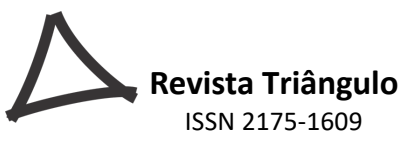

ORGANIZACIÓN PARA LA COOPERACIÓN Y DESARROLLO ECONÓMICO (OCDE). La definición y selección de competencias clave: resumen ejecutivo. Publicações OCDE. 2005. Disponível em:

http://deseco.ch/bfs/deseco/en/index/03/02.parsys.78532.downloadList.94248.DownloadFile.t mp/2005.dscexecutivesummary.sp.pdf Acesso em: 13 maio 17.

PEREIRA, G. A. M. O PISA como parâmetro de qualidade para as políticas educacionais: um estudo comparado entre Brasil e Espanha. 2016. 296 f. Tese (Doutorado em Educação). Universidade Federal do Paraná, Curitiba - PR. Disponível em: https://acervodigital.ufpr.br/handle/1884/43505 Acesso em: 23 maio 2018.

PETITAT, A. Produção da escola/produção da sociedade: análises sócio-históricas de alguns momentos decisivos da evolução escolar no Ocidente. Trad. E, Gruman. Porto Alegre, RS: Artes Médicas, 1994.

PETRONZELLI, V. L. L. Políticas de avaliação da educação escolar brasileira: ensaios dialéticos sobre a literacia matemática no PISA/OCDE. 2016. 148 f. Tese (Doutorado em Educação). Universidade Federal do Paraná, Curitiba-PR. Disponível em:

https://acervodigital.ufpr.br/bitstream/handle/1884/45695/R\%20-\%20T\%20\%20VERA\%20LUCIA\%20LUCIO\%20PETRONZELLI.pdf?sequence=1\&isAllowed=y. Acesso em: 23 maio 2018.

PINTO, D. F. S. OCDE: uma visão brasileira. Brasília: IRBr; FUNAG, 2000. RAMOS, B. S. S. O que significa isso? Dos slogans às ressignificações do discurso pedagógico contemporâneo. 2012. 191 f. Tese (Doutorado em Educação). Universidade do Estado do Rio de Janeiro - Rio De Janeiro. Biblioteca depositária: UERJ/REDE SIRIUS/BIBLIOTECA CEH-A, Disponível em: http://www.bdtd.uerj.br/tde_busca/arquivo.php?codArquivo=8687. Acesso em: 25 maio 2018.

ROCHA, M. C. Políticas de valorização do magistério: remuneração, plano de carreira, condições de trabalho - uma análise da experiência de Belo Horizonte. 2009276 f. Tese (Doutorado em Educação). Universidade de São Paulo - São Paulo. Biblioteca depositária: FEUSP. Disponível em: http://www.teses.usp.br/teses/disponiveis/48/48134/tde-05012010113240/pt-br.php Acesso em : 25 maio 2018.

RODRIGUES, E. O. (Des)construindo o conceito de inclusão: uma análise das políticas de ensino superior. 2017. Tese (Doutorado em Educação) Universidade Federal do Rio de Janeiro - Rio de Janeiro. Biblioteca depositária: biblioteca do CFCH. Disponível em: http://www.educacao.ufrj.br/ppge/teses2017/tElianeRodrigues.pdf. Acesso em: 25 maio 2018.

ROSA, M. G. O. Papel da OCDE na formulação e implementação de políticas de formação inicial/profissionalização de professores: os casos Brasil e Portugal (1990-2013). 2017. 327 f. Tese (Doutorado em Educação). Pontifícia Universidade Católica de Minas Gerais - Belo Horizonte - MG. Disponível em: file://C:/Users/susiv/Downloads/Educacao_RosaMG_1.pdf. Acesso em: 23 maio 2018. 

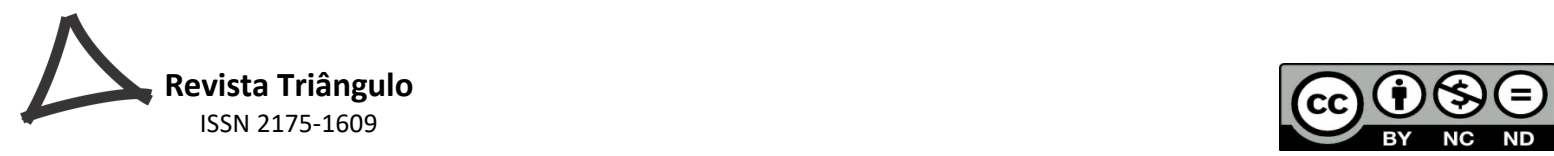

SANTOMÉ, J. T. Evitando o debate sobre a cultura no sistema educacional: como ser competente sem conhecimento. In: SACRISTÁN, J. G. et al. (Org.) Educar por competências: o que há de novo? Porto Alegre: Artmed, 2011.

SACRISTÁN, J. G. Dez teses sobre a aparente utilidade das competências em educação. In: SACRISTÁN, J. G. et al (Org.) Educar por Competências: o que há de novo? Porto Alegre: Artmed, 2011.

SILVA, C. R. V. Trabalho docente e inovação: a perspectiva da ocde para as políticas educacionais diante da globalização. 2015. 204 f. Tese (Doutorado em Educação). Universidade Federal do Paraná, Curitiba - PR. Disponível em:

https://www.acervodigital.ufpr.br/handle/1884/42018. Acesso em: 23 maio 2018.

SOSSAI, F. C. Pelos Gabinetes da OCDE. 2017. 265 f. Tese (Doutorado em Educação). Universidade do Estado de Santa Catarina, Florianópolis-SC. Disponível em: http://bdtd.ibict.br/vufind/Record/UDSC_dc2f657819517967ae2e3c94a05371e5\#details. Acesso em: 23 maio 2018. 